\title{
Oral Emulsion Dosage Form
}

National Cancer Institute

\section{Source}

National Cancer Institute. Oral Emulsion Dosage Form. NCI Thesaurus. Code C149713.

Liquid single-dose or multidose preparation consisting of an emulsion intended for oral use. Each dose from a multidose container is administered by means of a device suitable for measuring the prescribed volume, generally $5 \mathrm{~mL}$ or multiples thereof. 